\title{
Análise espaço-temporal de trajetórias tecnológicas rurais na Amazônia paraense
}

\section{Space-time analysis of rural technological trajectories in the Amazon Pará state}

Wanja Janayna de Miranda Lameira - Doutora em Ciências Ambientais, pela Universidade Federal do Pará (UFPA). Pesquisadora bolsista pelo Museu Emílio Goeldi. E-mail: wjlameira@hotmail.com

Arlete Silva de Almeida - Doutora em Ciências Ambientais, pela Universidade Federal do Pará (UFPA). Tecnóloga do Ministério de Ciências e Tecnologia lotada no Museu Paraense Emílio Goeldi. E-mail: arlete@museu-goeldi.br

Leila Sheila Silva Lisboa - Doutora em Ciências, pela Escola Superior de Agricultura "Luiz de Queiroz” (ESALQ-USP). E-mail: lisboa.leilass@gmail.com

\section{Resumo}

O objetivo deste estudo foi avaliar a cobertura e uso da terra para os anos de 2004, 2009, 2013 e 2018, com a perspectiva de identificar no espaço as mudanças de trajetórias tecnológicas rurais. Trata-se de um estudo experimental e interdisciplinar desenvolvido em células de $5 \times 5 \mathrm{~km}^{2}$ na faixa do arco do desmatamento. Os resultados indicam que a política da dendeicultura na região cumpre parcialmente as metas projetadas ao incorporar áreas de pastagens degradadas ao processo produtivo da dendeicultura, entretanto não impede a expansão do desmatamento, pois os remanescentes florestais continuam sendo suprimidos; observa-se também a mudança da trajetória tecnológica patronal T4 para a T5, com a homogeneização da paisagem para tais cultivos, principalmente a partir de 2009 na área de estudo. Tais informações podem auxiliar no planejamento territorial e na tomada de decisão para mitigar os descompassos do desenvolvimento agrário amazônico.

\section{Palavra-chave}

Dendeicultura. Trajetórias Tecnológicas. Geotecnologias. Amazônia.

\begin{abstract}
The purpose of this study is to evaluating land use cover change for the years 2004, 2009, 2013 and 2018, with a perspective of identify rural technological trajectories. This an experimental and interdisciplinary study was carried out in cells of $5 \times 5 \mathrm{~km}^{2}$ in the range of "arc deforestation". The results show that this policy partially fulfill the projected targets when incorporating areas of degraded pastures for palm oil, but it is not efficient to combat deforestation, as forest remnants continue to be suppressed. there is also to change the T4 patronal technological trajectories to T5with the homogenization of the landscape by oil palm plantations from 2009 in the study area. This information may can help in territorial planning and taking of decisions related to mitigation the irregularities existing in Brazil's amazon agrarian development.
\end{abstract}

\section{Keywords}

Palm Oil. Technological Trajectories. Geotechnologies. Amazon. 


\section{INTRODUÇÃO}

O Brasil lidera o ranking do desmatamento nas áreas tropicais, seguido de Índia, Indonésia, Sudão e Zâmbia (SAATCHI et al., 2007). No país, a maioria dos estudos realizados aponta a pecuária, a agricultura de corte e queima e a exploração madeireira como as principais causas dessas mudanças (RIVERO et. al., 2009; COELHO et al., 2010; MOUTINHO; GUERRA, 2018).

Os dados oficiais do Projeto de Monitoramento do Desmatamento na Amazônia Legal por Satélite (PRODES), do Instituto Nacional de Pesquisas Espaciais (INPE), têm mostrado que, embora os números do desmatamento tenham apresentado redução entre 2009 e 2014, nos últimos anos voltaram a ser alarmantes, passando de $6.207 \mathrm{~km}^{2}$ (2015), para $7.536 \mathrm{~km}^{2}$ (2018) e em torno de $9.762 \mathrm{~km}^{2}$ em 2019, sendo os estados do Pará e do Mato Grosso considerados os campeões em desmatamento na Amazônia Legal (INPE, 2018).

Tais números renovam as discussões acerca dessa temática na Amazônia, haja vista que o desmatamento é apontado como a principal fonte de emissões (46,1\%), seguido da atividade agropecuária (23,9\%) (AZEREDO et al., 2016). Essa pressão nas áreas de cobertura vegetal primária coloca em risco a manutenção da biodiversidade, altera o albedo terrestre, a composição química da atmosfera e os ciclos biogeoquímicos, modificando as trocas de energia entre a superfície terrestre e a atmosfera, alterando o padrão climático global (LAMBIN et al., 2003; FEARNSIDE, 2010).

Essa preocupação global levou o Brasil a assumir junto à ConvençãoQuadro das Nações Unidas sobre Mudança do Clima (UNFCCC) a Agenda 2030, para alcançar o desmatamento zero; restaurar e reflorestar 12 milhões de hectares de áreas desmatadas e 15 milhões de pastagens degradadas (ONU, 2017). Apesar desses esforços, as áreas de desmatamento continuam avançando na Amazônia (VERBURG et al., 2009; LAURANCE et al., 2011; COPERTINO et al., 2019), situação que torna imperativo o acompanhamento de tais mudanças, bem como a criação de políticas públicas eficazes na redução do desmatamento na região.

A produção sustentável de óleo de palma na Amazônia paraense faz parte dessa agenda internacional (ONU, 2017), cujas metas principais são reduzir o desmatamento e promover a inclusão social no campo. Desde então, observase uma tendência de mudança nos arranjos produtivos de alguns municípios paraenses da região nordeste.

Assim, o objetivo deste estudo foi avaliar a cobertura e uso da terra para os anos de 2004, 2009, 2013 e 2018, com a perspectiva de identificar no espaço as mudanças de trajetórias tecnológicas rurais. Trata-se de uma análise experimental, 
interdisciplinar desenvolvida em células de $5 \times 5 \mathrm{~km}^{2}$ na faixa do arco do povoamento consolidado - "arco do desmatamento" (BECKER, 2005), no município de Tomé-Açu, Pará. O estudo emprega metodologias complementares para avaliar a expansão da cobertura e uso da terra, com emprego de geotecnologias para identificar no espaço e no tempo as trajetórias tecnológicas do meio rural. Tais informações podem auxiliar no planejamento territorial e na tomada de decisão para mitigar os descompassos do desenvolvimento agrário amazônico, posto que relaciona três grandes linhas de investigação: a segurança alimentar com o fornecimento de alimentos essenciais a custos competitivos; a diversificação da matriz energética com a inclusão cada vez maior do uso de biomassa como fonte de energia e a sustentabilidade ambiental (VIEIRA FILHO, 2010).

\section{AS TRAJETÓRIAS TECNOLÓGICAS NO MEIO RURAL AMAZÔNICO E SUA RELAÇÃO COM AS MUDANÇAS NO USO DA TERRA}

Estudos têm demonstrado que há, pelo menos, seis padrões produtivos, bem definidos, na região amazônica, denominados de trajetórias tecnológicas do meio rural amazônico (COSTA, 2008, 2009, 2012), individualizadas a partir da compreensão da dinâmica da economia rural. São elas: três camponesas (T1, T2 e T3) e três patronais (T4, T5 e T6).

A trajetória camponesa $\mathrm{T} 1$, os sistemas produtivos convergem para culturas permanentes e pecuária de leite, que se constituem ponto de chegada da utilização primária de produtos florestais madeireiros e de culturas temporárias em formato de cultivos itinerantes (shifting cultivation); T2 - sistemas que convergem para atividades agroflorestais, em que a base é o extrativismo não madeireiro em combinação com a agricultura diversa (culturas temporárias e permanentes); T3 sistemas convergentes para pecuária de corte, em que as relações técnicas entre os camponeses são maisextensivas no que tange ao uso da terra.

A trajetória patronal T4 possui um conjunto de sistemas produtivos que convergem para a pecuária de corte, iniciando com a exploração de produtos madeireiros, seguido de plantio de culturas temporárias, até migrar para a pecuária de corte, requerendo sempre novos espaços; T5 - trata-se de uma trajetória autônoma, com sistemas especializados de culturas perenes praticadas em moldes empresariais (plantation - grandes extensões de plantiohomogêneo); e T6 - sistemas especializados em silvicultura, com baixa ocorrência na Amazônia.

As trajetórias no âmbito de mudança na cobertura e uso da terra referemse às sucessivas transições de uso observadas no tempo (MERTENS; LAMBIN 
2000). Segundo Azeredo et al. (2016), há pelo menos duas dimensões a serem consideradas: a temporal (instante inicial, instante final e passo de tempo de análise) e a descritiva (comportamento ao longo do tempo: sequência de estados e rapidez).

No espaço, esses padrões de uso da terra podem evidenciar diferentes tipos de sistemas produtivos no meio rural ao longo do tempo. Uma ferramenta potencial nesses estudos é o uso de imagens de satélites, que possuem uma periodicidade dos dados, baixo custo (BATISTELA; MORAN, 2009) e, de forma indireta, revelam como os agentes direcionam os recursos (naturais e institucionais) e seus procedimentos tecnológicos nos sistemas produtivos (SANTOS JÚNIOR et al., 2010).

\section{METODOLOGIA}

\section{1 ÁREA DE ESTUDO}

Foram selecionadas células de $5 \times 5 \mathrm{~km}$, cuja principal vantagem é a estabilidade espaço-temporal, pois a célula não está sujeita a modificações como a alteração de limites administrativos e a criação de novas unidades territoriais (IBGE, 2017). Utilizou-se como critérios de seleção a faixa do arco do desmatamento no estado do Pará (IBGE, 2015); a presença de estradas (IBGE, 2017); as áreas de dendezeiros de 2008 e 2013 (LAMEIRA; VIEIRA; TOLEDO, 2016); e a imagem de satélite de 2018 (USGS, 2018).

Cruzando esses dados, selecionou-se o município de Tomé-Açu, que está localizado no arco do desmatamento e possui aumentos consecutivos de dendezeiros na Amazônia paraense a partir de 2009. Das 257 células que cobrem o município de Tome-Açu, foram selecionadas 3 células $\left(75 \mathrm{~km}^{2}\right)$ onde havia presença de dendezeiros a partir de 2009 (PAM, 2018), caso contrário não seria possível avaliar as mudanças temporais das trajetórias tecnológicas rurais.

A área 1 está localizada às imediações das localidades Quatro Bocas, Água Branca, Cachoeira do Cravo e a Vila Maranhense. A área 2 está no eixo de ocupação do ramal da Jamique (área consolidada de ocupação japonesa), enquanto a área 3 encontra-se localizada mais ao sudeste do município de ToméAçu (Figura 1). Nessas áreas, o padrão de uso da terra tende a reproduzir a lógica de desenvolvimento exógeno, voltado para atender às demandas, principalmente do mercado externo das commodities agrícolas e minerais, que favorecem a desigualdade social (CASTRO; CAMPOS, 2015, p. 33). 
Figura 1 - Município de Tomé-Açu, Pará

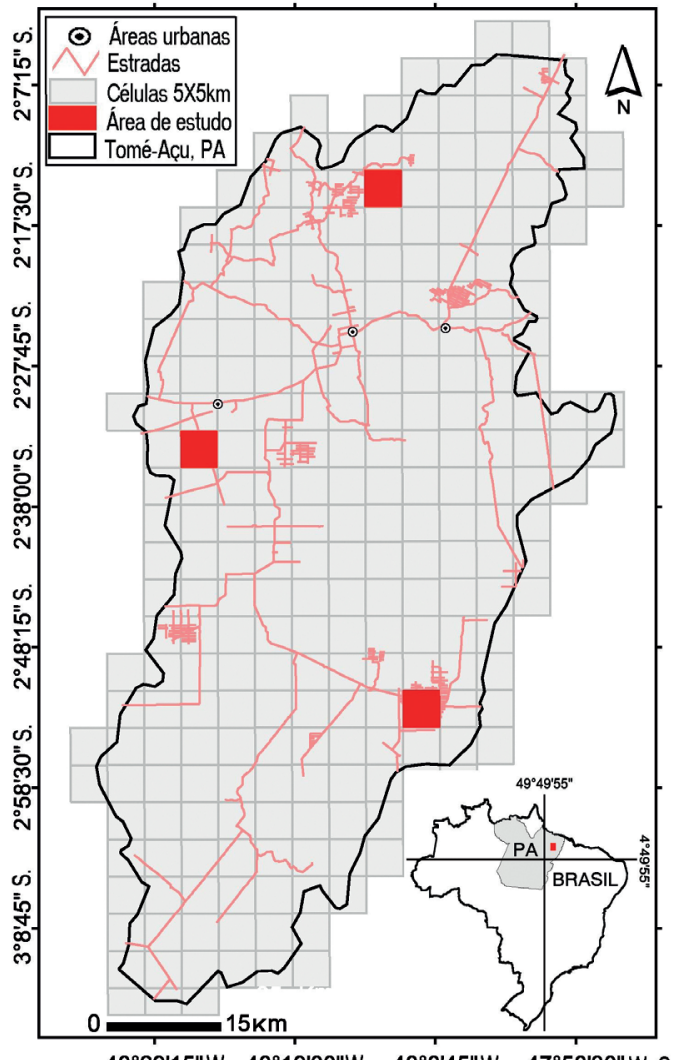

$48^{\circ} 29^{\prime} 15^{\prime \prime}$ W. $48^{\circ} 19^{\prime} 00^{\prime \prime}$ W. $48^{\circ} 8^{\prime} 45^{\prime \prime}$ W. $47^{\circ} 58^{\prime} 30^{\prime \prime}$ W. Gr.

Fonte: Organizada pelas autoras, 2019.

Esse panorama produtivo faz com que haja a predominância de trajetórias patronais ligadas à pecuária extensiva e à exploração madeireira em quase todos os estados da Amazônia Legal.

\subsection{DADOS E PROCEDIMENTOS TÉCNICOS}

\subsubsection{Análise da cobertura e uso da terra (2004 - 2018)}

Para aidentificação das classes temáticas, utilizaram-se as cenas 221063 e 221064 dos anos de 2004 e 2009 (Landsat TM-5, sensor TM 5, bandas 5, 4 e 3); 2013 e 2018 (Landsat 8, sensor OLI , bandas 6, 5 e 4, ortorretificadas) (USGS, 2018). Usaram-se, ainda, as imagens Geocover (INPE, 2000), que serviram de base para o georreferenciamento das imagens do Landsat TM-5. 
No pré-processamento, as imagens do Landsat TM-5 foram georreferenciadas com base em 30 pontos de controle, nas quais se aplicou o algoritmo de interpolação, baseado em triangulação e reamostragem pelo método de vizinhança mais próxima, obtendo-se um erro médio quadrático menor que um pixel $(30 \mathrm{~m}$ ) (ALMEIDA, et al., 2014). Em seguida, efetuou-se a retificação radiométrica para corrigir o valor do brilho das bandas quando estas apresentavam padrões diferenciados das demais imagens. Esta etapa é considerada como basilar em avaliações multitemporais por imagens de satélites. Realizaram-se, também, técnicas de realces de contraste nas imagens de satélite, para melhorar a interpretação visual e auxiliar na identificação dos intervalos de cinza ou DN, diferenciando as classes temáticas mediante técnicas de fatiamento de imagens (LAMEIRA; VIEIRA; TOLEDO, 2016).

Os dados obtidos por sensores remotos baseiam-se nas características espectrais da paisagem. Assim, utilizou-se como apoio o banco de dados de Lameira, Vieira e Toledo (2016) para o reconhecimento das principais feições da paisagem e calibração dos resultados obtidos nas classificações supervisionadas do município de Tomé-Açu. De posse desse acervo, aplicou-se a classificação supervisionada mediante a seleção de amostras espectrais selecionadas na imagem. O algoritmo utilizado foi o Máxima Verossimilhança (Maximum Likelihood).

Para reduzir a possibilidade de atribuir uma classe temática a outra diferente, a estratégia adotada na interpretação visual considerou os aspectos da cor, forma, tamanho, textura (impressão de rugosidade), a localização e o trabalho de campo. Outra estratégia foi generalizar as classes de cobertura vegetal e uso da terra em 7 (sete) classes: 1. Drenagem; 2. Floresta primária; 3. Floresta secundária; 4. Agropecuária; 5. Dendezeiros; 6. Solo exposto; e 7. Outros (nuvens, sombras).

$\mathrm{Na}$ validação das classes de cobertura e uso da terra, utilizou-se o índice Kappa (HUDSON; RAMM, 1987), gerado a partir da matriz de erro (matriz de confusão), que permitiu evidenciar os erros de inclusão e omissão. Em síntese, foram comparados os dados da expedição de campo com o resultado da classificação supervisionada. A avaliação quantitativa em conjunto dos dados das áreas de cobertura e uso da terra foi obtida por análise estatística simples de cálculo de área e porcentagem.

\subsubsection{Identificação espacial de trajetórias tecnológicas rurais na Amazônia paraense}

Com base nas 7 (sete) classes identificadas nas imagens de satélite, foram avaliadas neste estudo apenas as trajetórias tecnológicas patronais (COSTA, 
2008) mais facilmente identificáveis no espaço, porque estão conectadas à lógica empresarial, ocupando extensas áreas produtivas, representadas pela pecuária de grande porte e a agricultura em larga escala.

\section{RESULTADOS}

Os resultados das classificações de cobertura e uso da terra obtiveram precisão de aproximadamente 87,2\% (satisfatória), dos quais 12,6 foram erros de inclusão e 19,0 foram erros de omissão.

$\mathrm{Na}$ área 1 (Tabela 1), as mudanças mais significativas observadas de 2004 a 2018 são: (i) as áreas de florestas primárias, que em 2004 eram de 10,23 km² (40,92\%), gradativamente foram suprimidas por outros tipos de uso da terra em anos seguintes, contudo, em 2018 este percentual não ultrapassa 1\%; (ii) a vegetação secundária, em diferentes estágios sucessionais, teve aumento significativo de 2009 a 2013, já em 2018 teve uma queda de mais de 20\%; (iii) a atividade agropecuária apresentou expansão de 2004 a 2013; em anos seguintes as terras foram utilizadas para outras atividades; (iv) em contrapartida, as áreas de dendezeiros, inexistentes nessas áreas de 2004 a 2009, mais que triplicaram de 2013 a 2018.

Tabela 1 - Análise temporal das áreas de cobertura e uso da terra na área 1 (2004, 2008, 2013, 2018)

\begin{tabular}{l|r|r|r|r|r|r|r|r}
\hline \multirow{2}{*}{ CLASSES } & \multicolumn{2}{|c|}{$\mathbf{2 0 0 4}$} & \multicolumn{2}{c|}{2009} & \multicolumn{2}{|c|}{2013} & \multicolumn{2}{|c}{2019} \\
\cline { 2 - 9 } & $\mathrm{km}^{2}$ & \multicolumn{1}{c}{$\%$} & $\mathrm{~km}^{2}$ & $\%$ & $\mathrm{~km}^{2}$ & $\%$ & $\mathrm{~km}^{2}$ & \multicolumn{1}{c}{$\%$} \\
\hline Drenagem & 0,31 & 1,26 & 0,24 & 0,96 & 0,06 & 0,24 & 0,15 & 0,60 \\
\hline Floresta primária & 10,23 & 40,92 & 2,75 & 10,99 & 0,31 & 1,23 & 0,00 & 0,01 \\
\hline Floresta secundária & 3,41 & 13,64 & 11,48 & 45,92 & 16,85 & 67,41 & 11,09 & 44,37 \\
\hline Agropecuária & 6,07 & 24,27 & 9,12 & 36,49 & 2,24 & 8,96 & 0,68 & 2,70 \\
\hline Dendê & 0,00 & 0,00 & 0,00 & 0,00 & 2,75 & 10,99 & 11,97 & 47,89 \\
\hline Solo exposto & 4,94 & 19,77 & 0,74 & 2,94 & 1,65 & 6,61 & 1,11 & 4,42 \\
\hline Outros & 0,03 & 0,13 & 0,67 & 2,69 & 1,14 & 4,55 & 0,00 & 0,00 \\
\hline TOTAL & $\mathbf{2 5 , 0 0}$ & $\mathbf{1 0 0 , 0 0}$ & $\mathbf{2 5 , 0 0}$ & $\mathbf{1 0 0 , 0 0}$ & $\mathbf{2 5 , 0 0}$ & $\mathbf{1 0 0 , 0 0}$ & $\mathbf{2 5 , 0 0}$ & $\mathbf{1 0 0 , 0 0}$ \\
\hline
\end{tabular}

Fonte: Organizada pelas autoras, 2019.

Almeida (2015) avaliou a cobertura e o uso da terra em áreas localizadas no município de Moju e encontrou, em 1990, quase que $80 \%$ de floresta primária; valor este que em 2013 se aproximou de 20\%, significando perdas irreversíveis para o ecossistema. Esse padrão chega a ser uma característica da mesorregião nordeste paraense. Estas mudanças observadas no espaço e no intervalo temporal avaliados podem ser visualizadas na Figura 2: 
Figura 2 - Distribuição espacial das áreas de cobertura e uso da terra na área 1 (2004-2018)

\section{ÁREA 1}
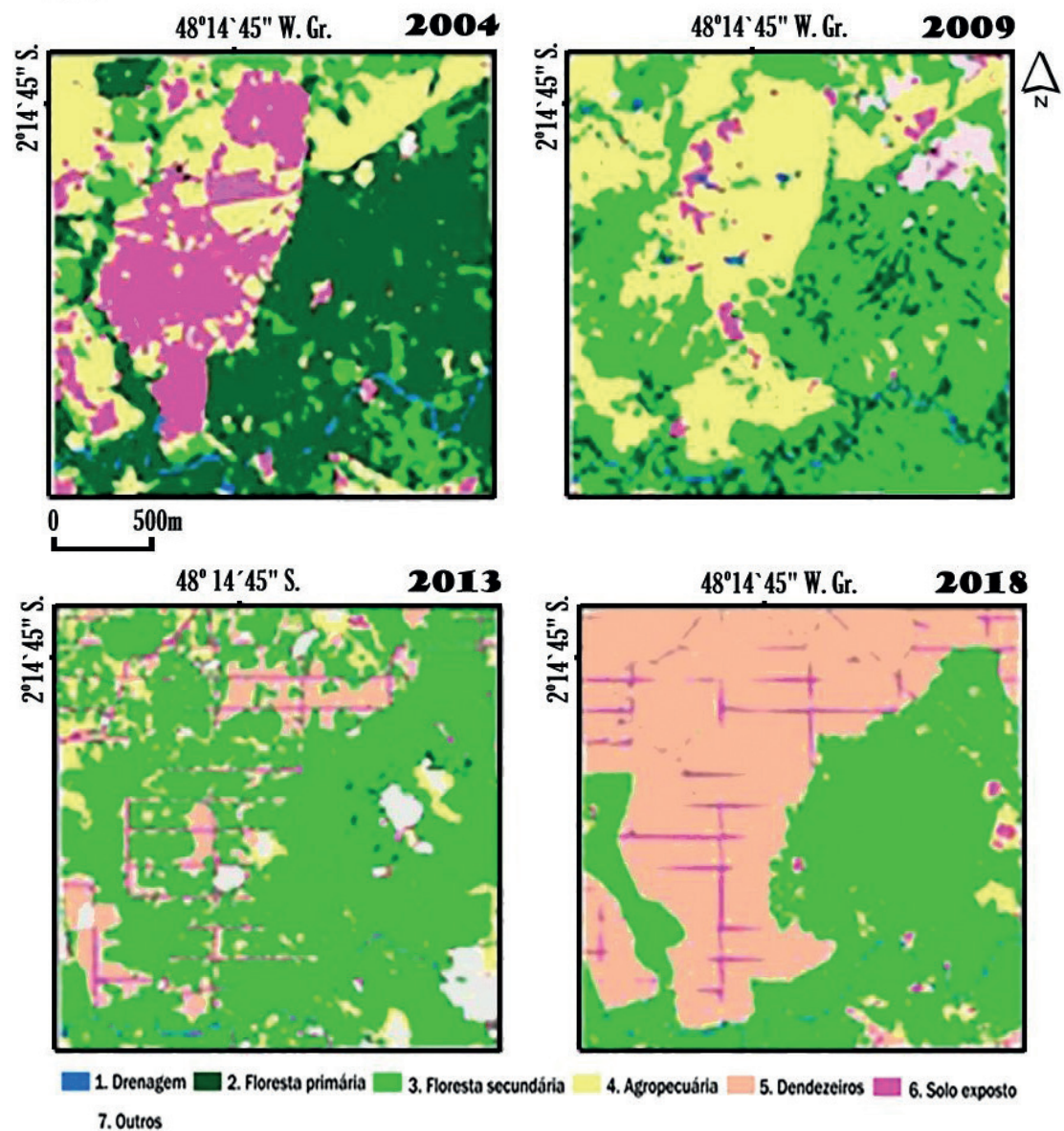

4. Agropecuária $\square$. Dendezeiros $\square$ 6. Solo exposto 7. Outros

Fonte: Organizada pelas autoras, 2019.

$\mathrm{Na}$ área 2 (Tabela 2), as principais mudanças foram: (i) a supressão considerável das florestas primárias de 2004 a 2009; de 2013 a 2018 elas são praticamente inexistentes; (ii) as áreas de vegetação secundária são as feições predominantes de 2004 a 2013, havendo uma redução acentuada em 2018; (iii) as áreas de agropecuária desde 2004 estão em processo gradual de redução; e (iv) os solos expostos permaneceram praticamente na mesma área de 2004 a 2009, de 17,96 $\mathrm{km}^{2}$ para 17,93 km², com redução em 2013 (4,65\%) e aumento em 2018 (17,80\%). 
Tabela 2 - Análise temporal das áreas de cobertura e uso da terra na área 2 (2004, 2008, 2013 e 2018)

\begin{tabular}{l|r|r|r|r|r|r|r|r}
\hline \multirow{2}{*}{ Uso da terra } & \multicolumn{2}{|c|}{$\mathbf{2 0 0 4}$} & \multicolumn{2}{c|}{2009} & \multicolumn{2}{c|}{2013} & \multicolumn{2}{|c}{2018} \\
\cline { 2 - 10 } & $\mathrm{km}^{2}$ & \multicolumn{1}{c}{$\%$} & $\mathrm{~km}^{2}$ & \multicolumn{1}{c}{$\%$} & $\mathrm{~km}^{2}$ & $\%$ & $\mathrm{~km}^{2}$ & \multicolumn{1}{c}{$\%$} \\
\hline Drenagem & 0,00 & 0,00 & 0,02 & 0,07 & 0,07 & 0,29 & 0,11 & 0,43 \\
\hline Floresta primária & 5,01 & 20,04 & 1,28 & 5,13 & 0,64 & 2,56 & 4,59 & 18,37 \\
\hline Floresta secundária & 6,86 & 27,44 & 11,70 & 46,81 & 13,49 & 53,97 & 8,60 & 34,41 \\
\hline Agropecuária & 8,64 & 34,56 & 7,52 & 30,06 & 5,07 & 20,26 & 4,44 & 17,77 \\
\hline Dendê & 0,00 & 0,00 & 0,00 & 0,00 & 3,56 & 14,22 & 4,45 & 17,80 \\
\hline Solo exposto & 4,49 & 17,96 & 4,48 & 17,93 & 1,16 & 4,65 & 2,81 & 11,22 \\
\hline Outros & 0,00 & 0,00 & 0,00 & 0,00 & 1,01 & 4,04 & 0,00 & 0,00 \\
\hline TOTAL & $\mathbf{2 5 , 0 0}$ & $\mathbf{1 0 0 , 0 0}$ & $\mathbf{2 5 , 0 0}$ & $\mathbf{1 0 0 , 0 0}$ & $\mathbf{2 5 , 0 0}$ & $\mathbf{1 0 0 , 0 0}$ & $\mathbf{2 5 , 0 0}$ & $\mathbf{1 0 0 , 0 0}$ \\
\hline
\end{tabular}

Fonte: Organizada pelas autoras, 2019.

As mudanças observadas no espaço e no intervalo temporal avaliados podem ser visualizadas na Figura 3:

Figura 3 - Distribuição espacial das áreas de cobertura e uso da terra na área 2 (2004-2018)
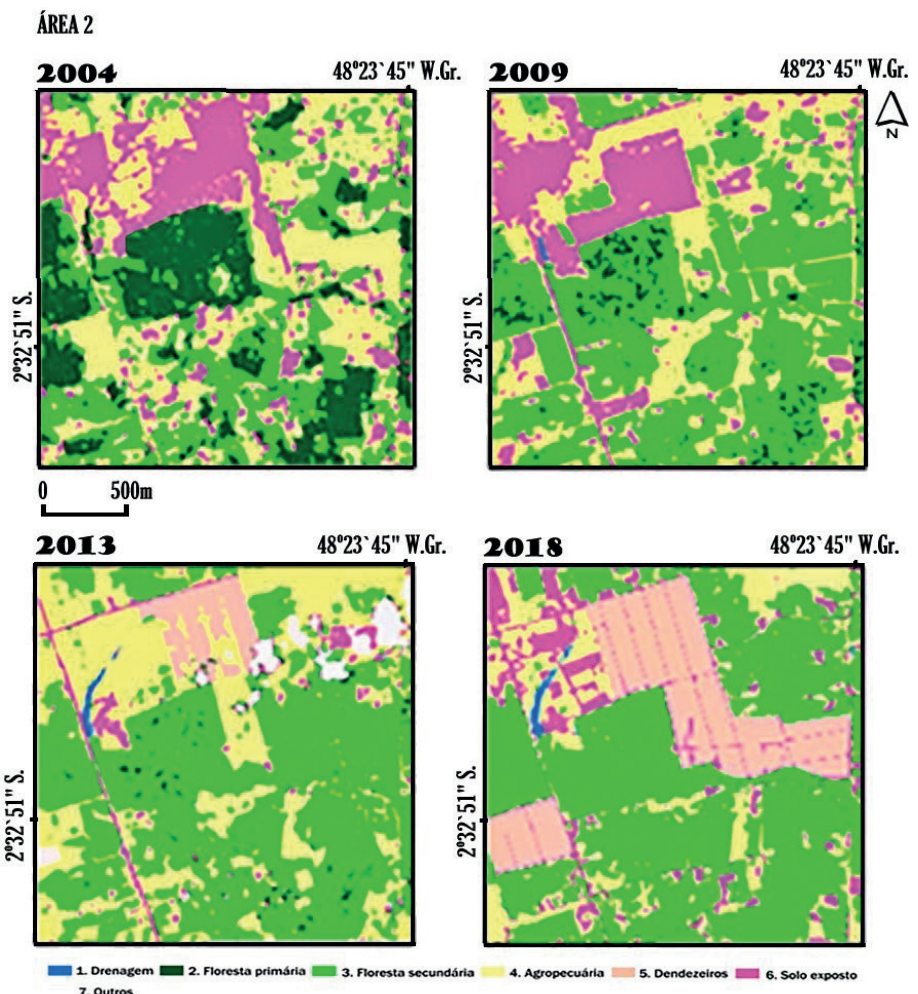

Fonte: Organizada pelas autoras, 2019. 
$\mathrm{Na}$ área 3 (Tabela 3), observa-se a contínua supressão das florestas primárias de 2004 a 2009, similar ao que foi observado nas áreas 1 e 2, onde as manchas de remanescentes florestais ainda ocupam 30\% da área de estudo. As demais classes tiveram oscilações variadas entre 2004 e 2018. A mudança de floresta primária para a agropecuária ou para o dendê é uma das tendências desta região, como observado por Nahum e Malcher (2012) e por Almeida e Vieira (2008) em estudos multitemporais na Amazônia.

Tabela 3 - Análise temporal das áreas de cobertura e uso da terra na área 3 (2004, 2008, 2013 e 2018)

\begin{tabular}{l|r|c|r|r|r|r|r|r}
\hline \multirow{2}{*}{ CLASSES } & \multicolumn{2}{|c|}{2004} & \multicolumn{2}{c|}{2009} & \multicolumn{2}{c|}{2013} & \multicolumn{2}{c}{2018} \\
\cline { 2 - 10 } & \multicolumn{1}{|c|}{$\mathrm{km}^{2}$} & \multicolumn{1}{c|}{$\%$} & $\mathrm{~km}^{2}$ & \multicolumn{1}{c}{$\%$} & $\mathrm{~km}^{2}$ & $\%$ & $\mathrm{~km}^{2}$ & $\%$ \\
\hline Drenagem & 0,00 & 0,00 & 0,00 & 0,00 & 0,00 & 0,00 & 0,10 & 0,38 \\
\hline Floresta primária & 12,26 & 49,04 & 9,50 & 38,00 & 8,87 & 35,49 & 7,50 & 30,00 \\
\hline Floresta secundária & 5,29 & 21,15 & 7,02 & 28,09 & 1,97 & 7,88 & 3,69 & 14,74 \\
\hline Agropecuária & 4,03 & 16,10 & 4,35 & 17,38 & 10,28 & 41,13 & 3,80 & 15,20 \\
\hline Dendê & 0,00 & 0,00 & 0,00 & 0,00 & 0,00 & 0,00 & 8,05 & 32,20 \\
\hline Solo exposto & 3,43 & 13,71 & 4,13 & 16,53 & 3,57 & 14,30 & 1,87 & 7,47 \\
\hline Outros & 0,00 & 0,00 & 0,00 & 0,00 & 0,30 & 1,20 & 0,00 & 0,01 \\
\hline TOTAL & $\mathbf{2 5 , 0 0}$ & $\mathbf{1 0 0 , 0 0}$ & $\mathbf{2 5 , 0 0}$ & $\mathbf{1 0 0 , 0 0}$ & $\mathbf{2 5 , 0 0}$ & $\mathbf{1 0 0 , 0 0}$ & $\mathbf{2 5 , 0 0}$ & $\mathbf{1 0 0 , 0 0}$ \\
\hline
\end{tabular}

Fonte: Organizada pelas autoras, 2019.

Quanto às mudanças da cobertura vegetal, a informação mais significativa para os anos de 2004, 2009, 2013 e 2018 é que há um padrão regular e gradativo das manchas de áreas remanescentes, em especial a partir de 2009. Isto reforça a ideia de que há uma pressão das políticas públicas para permitir que a palma de óleo substitua a vegetação nativa em propriedades privadas que possuem déficits de restauração florestal (LEES; VIEIRA, 2013) e podem causar conflito de interesse com as metas sustentáveis, tendo como pano de fundo a política dos biocombustíveis na Amazônia paraense.

Ao considerar as classes de agropecuária em relação aos dendezeiros (Figura 5), observa-se que a expansão da dendeicultura na Amazônia está fortemente associada às políticas públicas, com dinâmicas de ações complexas, que atuam em escalas globais e regionais. Portanto, é basilar compreender onde ocorrem e qual a velocidade dessas mudanças nos processos produtivos da região. 
As principais alterações na área 3 podem ser visualizadas na Figura 4:

Figura 4 - Distribuição espacial das áreas de cobertura e uso da terra na área 3 (2004-2018)

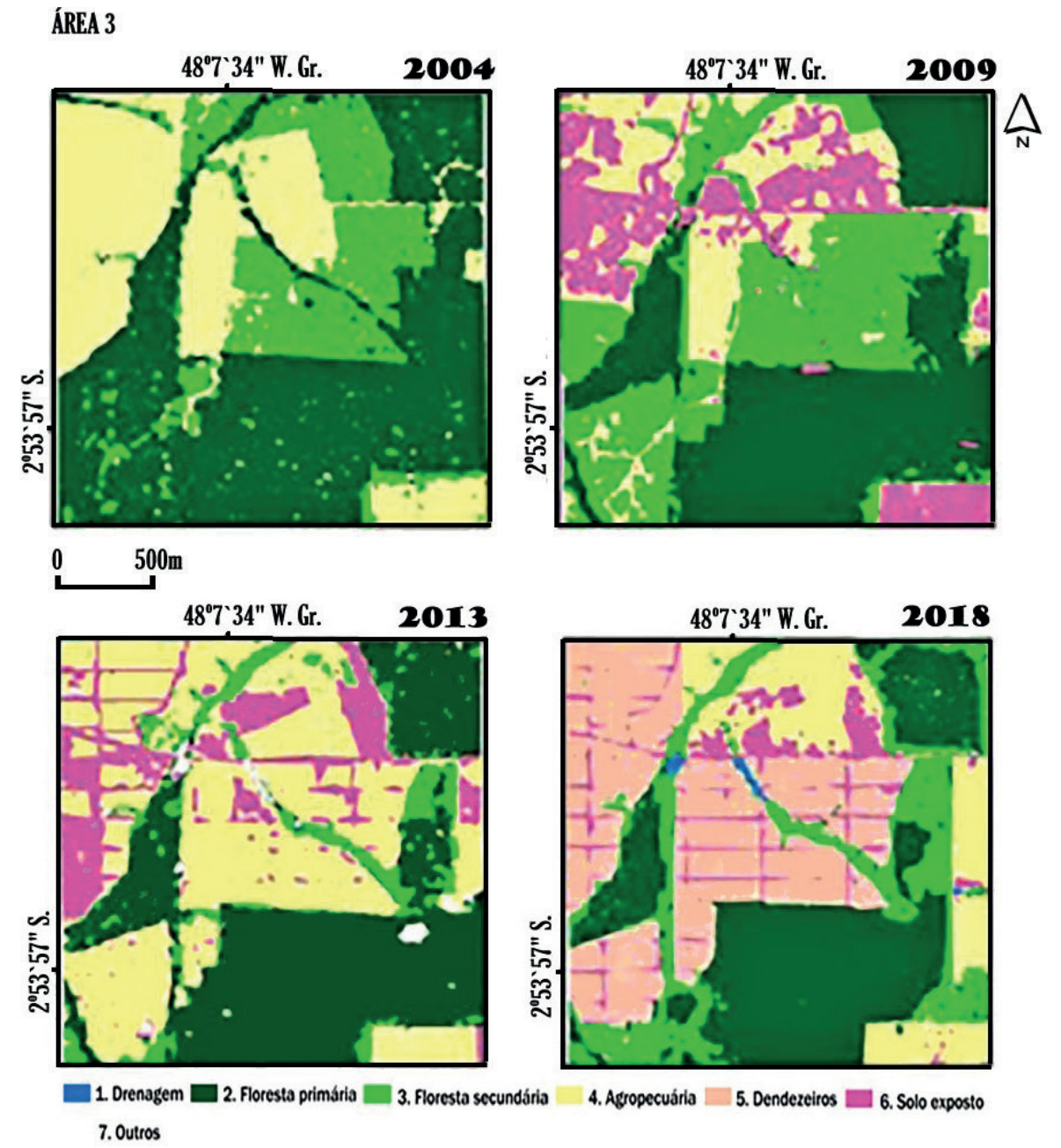

Fonte: Organizada pelas autoras, 2019.

Assim, com base na classificação de trajetórias tecnológicas do meio rural amazônico de Costa (2012), pode-se inferir que há uma tendência de mudança da trajetória patronal T4 (sistemas de produção que convergem para pecuária de corte) para a T5, em que há tendência à homogeneização da paisagem, com a instalação de áreas com plantios de dendezeiros. 
Figura 5 - Tendência preliminar de mudança de trajetórias tecnológicas rurais na Amazônia paraense (2004-2018)
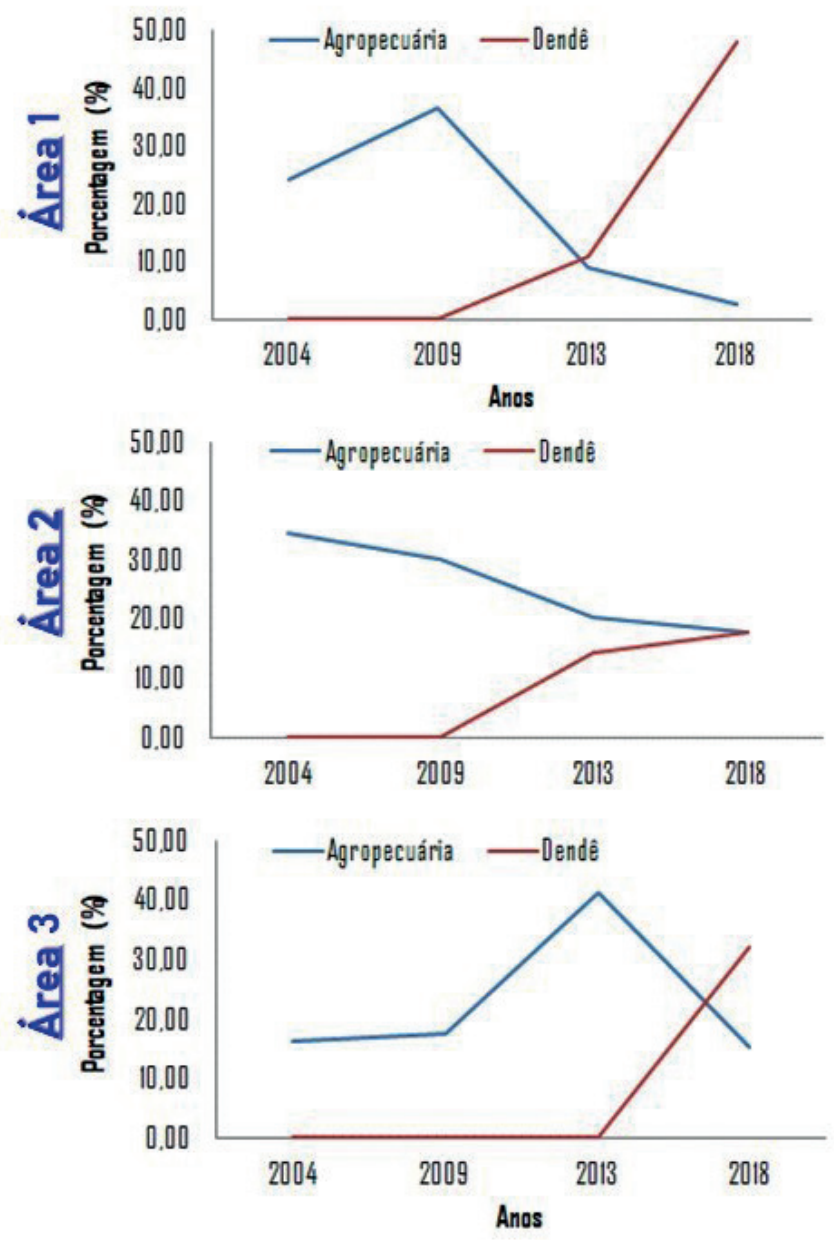

Fonte: Organizada pelas autoras, 2019.

\section{CONSIDERAÇÕES FINAIS}

A expansão do uso da terra na Amazônia paraense voltada para os cultivos da palma de óleo é parte de uma agenda política sustentável.

Nosso estudo mostra que esta política cumpre parcialmente as metas projetadas, posto que tais cultivos passaram a ocuparprincipalmente as manchas de pastagem degradada, não sendo capazes de conter o desmatamento, uma vez que os remanescentes florestais continuam sendo suprimidos. Identifica, 
também, a tendência de mudança da trajetória patronal T4 (sistemas de produção que convergem para pecuária de corte) para a T5, com a homogeneização da paisagem pelo aumento dos cultivos de dendezeiros.

Essa tentativa de identificar, no espaço, as trajetórias tecnológicas do meio rural amazônico, mediante a compreensão das mudanças de uso da terra, contém limitações que devem ser melhoradas como emprego de sensores orbitais de alta resolução espacial, objetivando idividualizar os cultivos agroflorestais e os pequenos mosaicos de ocupação da agricultura familiar. Cabe destacar ainda que é necessário aprofundar a discussão acerca dos drives forcing, que são as causas e/ou as consequências dessa homogeneização. O diferencial deste estudo é a capacidade de identificação dos padrões produtivos no território, contribuindo com o monitoramento espaço-temporal das dinâmicas agrárias da Amazônia paraense.

\section{REFERÊNCIAS}

ALMEIDA, A. S. Mudanças de usos da terra em paisagens agrícolas com palma de óleo (Elaeis Guineenses Jacq.) e implicações para a biodiversidade arbórea na Amazônia Oriental. 2015116 f. Tese (Doutorado em Ciências Ambientais) - Universidade Federal do Pará/ Embrapa Amazônia Oriental/ Museu Paraense Emílio Goeldi, Belém, 2015.

ALMEIDA, A. S.; VIEIRA, I. C. G. Dinâmica da cobertura vegetal e uso da terra no município de São Francisco do Pará (Pará, Brasil) com o uso da técnica de sensoriamento remoto. Boletim do Museu Parense Emílio Goeldi, Belém, v. 3, n. 1, p. 81-92, 2008.

ALMEIDA, A. S.;VIEIRA, I. C. G.; BARROS, M. N. R.; ROCHA, E D. P. N. Áreas de endemismo Belém e Xingu: Configuração e espacialização do uso da terra e da cobertura vegetal. In: EMILIO, T.; LUIZÃO, F. (org.). Cenários para a Amazônia: clima biodiversidade e uso da terra. Manaus: Editora INPA, 2014. p. 57-66.

AZEREDO, M.; MONTEIRO, A. M. V.; ESCADA, M. I. S.; REIS, K.; VINHAS, L. Mineração de Trajetórias de Mudanças de Cobertura da Terra em Estudos de Degradação Florestal. Revista Brasileira de Cartografia, Uberlândia,v. 68, n.4, p. 717-731, 2016.

BATISTELLA, M.; MORAN, E. F. Geoinformação e monitoramento ambiental na América Latina. São Paulo: Oficina de Textos, 2009. 424 p. 
BECKER, B. Geopolítica da Amazônia. Estudos Avançados, São Paulo, v. 19, n. 53, p. 71-86, jan./abr. 2005.

CASTRO, E.; CAMPOS, I. (org.). Formação socioeconômica da Amazônia. Belém: NAEA, 2015. 640 p. (Coleção Formação Regional da Amazônia, 2). Disponível em: https://ppgdse.ufma.br/uploads/files/Formacao $\% 20$ Socioeconomica\%20da\%20Amazonia.pdf. Acesso em: 30 dez. 2018.

COELHO, M. C. N.; MIRANDA, E.; WANDERLEI, L. J.; GARCIA, T. C. Questão energética na Amazônia: disputa em torno de um novo padrão de desenvolvimento econômico e social. Novos Cadernos NAEA, Belém, v. 13, n. 2, p. 83-102, dez. 2010. Disponível em: http://www.periodicos.ufpa.br/index. $\mathrm{php} / \mathrm{ncn} /$ article/viewFile/475/739. Acesso em: 30 jun. 2018.

COPERTINO, M.; PIEDADE, M. T. F.; VIEIRA, I. C. G.; BUSTAMANTE, M. Desmatamento, fogo e clima estão intimamente conectados na Amazônia. Ciência e Cultura, São Paulo, v. 71, n. 4, p. 4-5, out./dez. 2019.

COSTA, F. A. Heterogeneidade estrutural e trajetórias tecnológicas na produção rural da amazônia: delineamentos para orientar políticas de desenvolvimento. In: BATISTTELA, M.; MORAN, E. F.; ALVES, D. S. (org.). Amazônia: natureza e sociedade em transformação. São Paulo:EDUSP, 2008. p. 137-180.

COSTA, F. A. Desenvolvimento agrário sustentável na Amazônia: trajetórias tecnológicas, estrutura fundiária e institucionalidade.In: BECKER, B. K. (org.). Um projeto para a Amazônia no século 21: desafios e contribuições. Brasília:Centro de Gestão e Estudos Estratégicos, 2009. p. 215-363.

COSTA, F. A. Mercado de terras e trajetórias tecnológicas na Amazônia. Economia e Sociedade, Campinas, v. 21, n. 2, p. 245-273, ago. 2012.

FEARNSIDE, P.M. Estoques e fluxos de carbono na Amazônia como recursos naturais para geração de serviços ambientais. In: BUENAFUENTE, S. M. F. (org.). Amazônia: dinâmica do carbono e impactos socioeconômicos e ambientais. Boa Vista, RR: Editora da Universidade Federal de Roraima, 2010. p. 27-56.

HUDSON, W. D.; RAMM, C. W. Correct formulation of the kappa coefficient of agreement. Photogrammetric Engineering e Remote Sensing, Maryland, v. 53, n. 4, p. 421-422, 1987.

IBGE. Malha municipal digital: escala 1:250.000. IBGE, Rio de Janeiro, RJ, 2015. Disponível em: http://www.ibge.gov.br.php. Acesso em: 21 jun. 2018. 
IBGE. Produção agrícola municipal (PAM) de 2017. IBGE, Rio de Janeiro, RJ, 2017. Disponível em: http://www.ibge.gov.br. Acesso em: 12 jun. 2018.

INPE. Catálogo de imagens: Landsat Geocover - GLCF. INPE, Brasilia, DF, 2000. Disponível em: http://www.dgi.inpe.br/CDSR/. Acesso em: 12 maio 2017.

INPE. Banco de dados do projeto PRODES, 2018.INPE, Brasília, DF, 2018. Disponível em: http://www.dpi.inpe.br/prodesdigital/prodes.php. Acesso em: 15 abr. 2018.

LAMBIN, E. F., GEIST, H. J., LEPERS, E. Dynamics of land-use and landcover change in tropical regions. Annual Review of Environment and Resources, [S.l.], v. 28, n. 1, p. 205-241, 2003.

LAMEIRA, W.J.; VIEIRA, I. C. G.; TOLEDO, P. M. Panorama da sustentabilidade na fronteira agrícola de bioenergia na Amazônia. Sustentabilidade em Debate, Brasília, v. 6, n. 2, p. 193-210, maio/ago. 2015.

LAURANCE, W. F.; CAMARGO, J. L. C.; LUIZÃO, R. C. C.; LAURANCE, S. G.; PIMM, S. L.; BRUNA, E. M.; STOUFFER, P. C.; WILLIAMSON, B.; BENÍTEZ-MALVIDO, J.; VASCONCELOS, H. L.; HOUTAN, K. S. V.; ZARTMAN, C. E.; BOYLE, S. A.; DIDHAM, R. K.; ANDRADE, A.; LOVEJOY, T. E. The fateofAmazonianforestfragments: a 32-year investigation. Biological Conservation, [S. l.], v. 144, p. 56-67, 2011.

LEES, A. C.; VIEIRA, I. C. G. Oil-palm concerns in Brazilian Amazon. Nature, Basingstoke, v. 497, p. 188, May 2013.

MERTENS, B.; LAMBIN, E. F. Land-cover-change trajectories in Southern Cameroon. Annals of the Association of American Geographers, [S. l.], v. 90, p. 467-494, 2000.

MOUTINHO, P.; GUERRA, R. O desmatamento na floresta amazônica em 2016: o dragão acordou. IPAM Amazônia, Belém, 2018. Disponível em: http:/ / ipam.br/wp-content/upload/2016/12/prodes.png. Acesso em: 03 jun. 2018.

NAHUM, J. S.; MALCHER, A.T.C. Dinâmicas territoriais do espaço agrário na Amazônia: a dendeicultura na microrregião de Tomé-Açu (PA). Revista Confins (online), Paris, n. 16, 2012. Disponível em: http://confins.revues.org/7793. Acesso em: 22 jan. 2013. 


\section{ONU. Glossário de termos do Objetivo de Desenvolvimento Sustentável}

13: tomar medidas urgentes para combater a mudança do clima e seus impactos. Brasília, DF: Organização das Nações Unidas no Brasil, 2017. 52 p. Disponível em: https://www.undp.org/content/dam/brazil/docs/ODS/glossario13.pdf. Acesso em: 04 jun. 2018.

RIVERO, S. ; ALMEIDA, O.; ÁVILA, S.; OLIVEIRA, W. Pecuária e desmatamento: uma análise das principais causas diretas do desmatamento na Amazônia. Nova Economia, Belo Horizonte, v. 19, n. 1, p. 41-66, 2009.

SAATCHI, S. S.; HOUGHTON, R. A.; SANTOS AVALA, R. C.; SOARES, J. V.; YU, Y. Spatial distribution of above ground live biomas in Amazon basin. Global Change Biology, [S. l.], v. 13, p. 816-837, 2007.

SANTOS JÚNIOR, R. A. O.; COSTA, F. A.; AGUIAR, A.P. D.; TOLEDO, P. M.; VIEIRA, I. C. G.; CÂMARA, G. Desmatamento, trajetórias tecnológicas rurais e metas de contenção de emissões na Amazônia. Ciência e Cultura, São Paulo, v. 62, n. 4, p. 56-59, 2010.

USGS. Imagens orbitais digitais gratuitas do satélite Landsat-8: data de passagem 04/03/2017 EUA. USGS, Brasília, DF, 2018. Disponível em: http://landsat. usgs.gov. Acesso em: 21 jan.2018.

VERBURG, P. H.; VAN DE STEEG, J.; VELDKAMP, A.; WILLEMEN, L. From land cover change to land function dynamics: A major challenge to improve land characterization. Journal of Environmental Management, [S. l.], v. 90, n. 3, p. 1327-1335, 2009. 